\title{
Criteria for Evaluating Qualitative Research
}

\author{
Valerie Anderson \\ University of Portsmouth, \\ Richmond Building \\ Portland Street \\ Portsmouth, UK \\ PO1 3DE \\ Valerie.anderson@port.ac.uk \\ $+44(0) 2392844029$
}

\section{Criteria for Evaluating Qualitative Research}

Within human resource development (HRD) there is an increasing call for in-depth qualitative research to enhance the evidence-base associated with the field. However, like the HRD community across the world, the qualitative research community is a disparate one. Different scholars draw on a range of research strategies that include (and are not limited to): case study, ethnography, phenomenology, grounded theory, biographical, narrative, historical and participatory inquiry (Denzin, 2017). Qualitative research is a vibrant and emerging field; different epistemological and disciplinary positions are represented and, given the emergent and diverse nature of the field, it is not surprising that no consensus has been achieved about 'rigor'. Indeed, even the term 'rigor' is contested (Barusch, Gringeri, \& George, 2011).

As the leading journal concerned with empirical research in the HRD field the editors of Human Resource Development Quarterly (HRDQ) are clear that researcher reputation, citation, and impact scores are not simple 'proxies' for research quality; nor are they the basis of judgements of our own work and that of others (cf. Denzin, 2017). As the field of research continues to develop, in both predictable and unexpected ways, it is important that we continuously review and clarify our editorial expectations of criteria for quality and excellence in qualitative research and so this editorial addresses two questions:

- How is HRD research and scholarship enriched through qualitative research?

- What criteria are appropriate for evaluating the quality of qualitative research?

In addressing these questions we focus on qualitative research; the field of mixed methods research is outside our scope. Rigor in mixed methods and in quantitative research will be the subject of subsequent editorials. Our criteria are built upon the insights and experiences of qualitative researchers from a variety of disciplinary traditions and, where possible, we indicate exemplar work from the HRD field to illustrate our points.

\section{The Nature of Qualitative Research and the Nature of Rigor}

Qualitative research in HRD is generated from a porous research field that is constantly expanding and maturing. As with other practice-based fields, the term 'qualitative research' in HRD does not represent a monolithic, agreed-upon approach; rather it is populated by a multitude of perspectives and 'voices' (Henry, 2015). Qualitative research is characterised by the importance attached to interpretive, naturalistic and holistic inquiry. In spite of a wide variety of outlooks, opinions and research practices among qualitative researchers, they share an assumption about the existence of 
multiple realities understood as intangible, contextually located and shaped and maintained or transformed by the experiences and meanings of participants (Henry, 2015). In this multi-faceted field research paradigms are an important issue for debate and clarity. Most quantitative research in the HRD field is grounded in the assumptions of positivism or post-positivism but the approach of qualitative researchers is positioned in a range of different paradigmatic perspectives that include, but are not limited to, critical theory, interpretivism, feminism, constructivism and critical realism. This has consequences for the nature of rigor and for the use of terms such as validity. Rigor is understood by researchers to characterise the trustworthiness, credibility and plausibility of research as judged by the use of theory, research design, data generation and data analysis. Rigor is important but, from the perspective of some transformative paradigms, this understanding of rigor is problematically limited as it excludes consideration of the motivation and purpose of research and the social or community-related effects of research outcomes (Dellinger \& Leech, 2007). All researchers, whether qualitative or quantitative, might agree that rigorous research is not necessarily 'good' research; many who undertake qualitative research prioritize additional criteria relating to professional and ethical practice as the basis from which to establish the value of the research endeavour (Barusch et al., 2011; Walby \& Luscombe, 2016).

The editorial policy of HRDQ is to encourage and publish quantitative, qualitative and mixedmethods approaches. With such an inclusive approach HRD scholars and HRDQ authors, readers and reviewers might imagine themselves to be, from time to time, faced with an imaginary chasm in relation to rigor (Walby \& Luscombe, 2016). For quantitative researchers in the HRD field and within the Academy of Human Resource Development (AHRD) ideas about rigor form part of a dominant tradition of science and scholarship developed and matured over many centuries. On another side of this 'chasm' stand qualitative researchers who, although increasing in confidence and expertise, find themselves needing to justify the credibility, trustworthiness, value and legitimacy of their work. In a context where qualitative research does not claim to be 'scientific' and 'objective' but rather seeks to engage in sense-making or interpretation of phenomena in terms of the meanings, values, beliefs and experiences of people (Denzin \& Lincoln, 2011), qualitative researchers are accused of lacking 'truth criteria' and using an 'anything goes' methodology that is not replicable and cannot be generalized. Such claims lead to allegations that qualitative research yields low quality, 'soft journalistic' results that are closer to common sense or even fiction, rather than representing scientifically rigorous outcomes (Denzin, 2017). As we seek to encourage the very best empirical research, therefore, we must commit ourselves to continuous review of criteria for evaluating the quality of manuscripts we receive. We acknowledge enduring debates about the nature of rigor and the attempts made to develop schemas to characterise alternative approaches to issues such as validity associated with positivist, postpositivist, poststructuralist, and postmodernist research paradigms (Onwuegbuzie \& Leech, 2007). Such attempts highlight important issues associated with construct validation; inferential consistency; utility and evidence use and consequential validity (Dellinger \& Leach, 2007). I acknowledge that different theoretical approaches foreground different evaluation criteria; the rigor issues for grounded theory will not be identical to those for phenomenology or for more general interpretations offered by thematic analysis (Braun \& Clarke, 2006). 'Blanket' criteria for rigor cannot be applied in our evaluation of manuscripts as different criteria will make more or less sense for different research genres, strategies and disciplines. It is unrealistic to expect all the criteria I include here to be evident in every qualitative submission. The criteria I describe first are 'pre-requisites' of good quality submissions in any non-positivist submission, however, and we recommend potential authors to ensure clarity about them in their work.

Evaluation Criteria for Qualitative Research 
The following criteria are important for all qualitative submissions. They build on the criteria for the evaluation of qualitative research set out by Rocco (2010) and are ordered here to reflect the 'flow' of research projects accepting that most qualitative research requires a recursive rather than a linear process and some crossover is inevitable. These criteria are not totally distinct from one another, nor do they need to be.

1. Communication of methodological awareness evidenced by an audit trail. 'Meaningful coherence' (Tracy, 2010) is a pre-requisite of qualitative submissions. This involves thoughtful identification and application of the choices and research design strategies enacted in the research project under discussion. This will be justified by reference to research context and research questions. Rocco (2010) identified the importance of a well-articulated problem as the core of a good qualitative research paper and we go further, arguing that evaluation of the research also requires an assessment of how well a study 'hangs together' around the question being addressed. This requires attention to whether methods and techniques have been used that are consistent with the research questions (Tracy, 2010). In short, the criterion here is: can the reader have confidence that there is an audit trail that records and explains all the steps taken and decisions made in the research process, from establishing the research question at the beginning to the design issues and the approach taken to data analysis?

2. Sampling strategy, sample size and data or theoretical saturation.

a. The mechanisms of sample selection used in qualitative research form an important issue in relation to rigor (Barusch et al., 2011). As the field of qualitative research has developed over time too much of it has, in my view, been based on unjustified, accidental or opportunistic sampling strategies. I look forward to more submissions using sampling approaches such as purposive or quota sampling. Good quality work will include an explanation and justification of the choice of research site(s), organizational location(s), contextual setting(s) and recruitment and selection of participants. A good example of clarity in relation to sample selection is provided by (Mueller \& Lovell, 2015).

b. Data access procedures can provide further evidence of rigor. Good qualitative research outcomes rely on more than 'physical' access to data sources. Discussion of steps taken to achieve cognitive access (Saunders, Lewis \& Thornhill, 2016) are necessary. I expect authors to reflect about the procedures used to establish sufficient trust between the researchers and the research participants (Burkett \& Morris, 2015) so that there can be confidence that their data set represents meaningfully authentic and 'rich' meanings, experiences and perceptions. The work of Muir (2014) provides a useful exemplar of this in HRD research.

c. Issues of sample size have also been subject to intensive debate over time. My position here is that 'size does matter' but that 'more is not always better'. I acknowledge that sample size decisions cannot be made at the outset of many qualitative inquiry processes. However, when the point of formulating conclusions approaches it is important to justify that the sample size was sufficient. Often the term 'saturation' is used too loosely and the concept appears to be misunderstood (Nelson, 2016). In its origins, as a part of a grounded theory approach, saturation was defined by Glaser and Strauss (1967) as a judgement that no additional data would be found to further develop the 'properties' of an analytic category. Although a tenet of qualitative research is that further variation is always likely, saturation is taken to have occurred when further data gathering and analysis will add very little to the conceptualization; similar instances 
begin to be observed over and over again (Strauss \& Corbin, 2015). However, 'saturation' is not the same as repetition of stories or events in the data as a claim that 'nothing new happened'. Following Nelson (2016), I argue that claims of saturation require justification based on an appropriate combination of evidence that might include some of the following:

i. A data set that supports a conceptualization that incorporates a rich network of concepts and themes with complex, rather than over-simple, connections. Tracy (2010) argued that rich rigor in qualitative data will demonstrate 'requisite variety' meaning that for research to accurately account for the phenomenon under investigation then it must be at least as complex (Hart, 2000). Although a rule of parsimony is held in esteem in quantitative research, qualitative phenomena require complex means of data collection, analysis, and explanation.

ii. Data presentation that makes use of a range of evidence to illustrate the concepts; reliance on one or two sources suggests that saturation has not been achieved.

iii. A resonance with the different features of the existing literature base(s) or applied social contexts in the area(s) being investigated.

iv. Evidence of negative case analysis where conceptual revision processes have been undertaken until potentially 'negative' or 'deviant' features of the data are included in the conceptualization.

3. Member-checking procedures are another expected feature of qualitative research to verify 'the fair representation and 'confirmability' of participant voices and feedback (Choi \& Roulston, 2015) to provide evidence of what some, but not all, qualitative researchers might refer to as internal validity (Dellinger \& Leech, 2007). Throughout the history of qualitative research, verification of data, analytic categories, interpretations, and conclusions with members of groups from whom the data were originally collected has been accepted as an important technique for establishing credibility. Good quality submissions will explain their procedures for member-checking.

4. The absence of reflexivity on the part of the researcher in much published qualitative research in HRD is surprising although Wang and Roulston (2007) provided a useful discussion of this issue. Perhaps this results from a fear on the part of authors that it would be unprofessional or intrusive to disclose their personal characteristics and from a concern that editorial preferences might favour a 'disinterested detachment' from the phenomenon under research. However, the acknowledged subjectivity of qualitative methods and the importance of the 'researcher's lens' in qualitative research requires a discussion of the researcher's context, positionality or standpoint, and the possible effect of this on the research process and outcomes (Muir, 2014). This is one of the key criteria for rigor in qualitative studies.

5. Ethical issues represent a further area where discussion is disappointingly absent in much published qualitative research in HRD although Tosey, Lawley, and Meese (2014) are an exception. Researchers and editors are increasingly aware of the issues of institutional review boards and informed consent arrangements before publication can be considered. However, in qualitative research there may also be 'situational ethics'; dilemmas may occur as the traditional power relationships of researcher-research subject are reconstructed into an ongoing relationship between the researcher(s) and the research participants who are being encouraged to engage in sharing meaningful accounts of their perceptions, experiences and feelings. A further set of ethical issues surrounding 'exiting ethics' (Tracy, 2010) may require discussion. These issues are extensively considered by Miller, Birch, Mauthner and Jessop (2012) and their colleagues. Situational ethics and 'exiting ethics' may arise from the unique circumstances of a 
particular research context and we expect to see discussion of the ethical obligations and accountabilities resulting from these choices in qualitative papers submitted to HRDQ.

6. Transferability is another expected feature of discussion in qualitative submissions (Poduthase, Walby \& Luscombe, 2016; Poduthase, 2015). Statistical generalizability is not desirable or reasonable in qualitative research but qualities of 'thick description' that present findings with categories identified that are appropriately defined and supported by sufficient data are expected. This can be achieved through the presentation of rich, direct quotations or the authors' own words, descriptive phrases or experiences that convey a sense of the participants and their environment as the basis for careful interpretation to illustrate in-depth concepts and constructs that are important to the study. This can provide the basis for consideration of the potential for application to other times, places, people, and contexts as a useful indicator of rigor.

To summarise, we expect these six criteria to be represented in qualitative research studies that claim a rigorous approach: reflexivity; methodological coherence; sampling and data access issues; member-checking of data collected; discussion of transferability, and ethical issues. Other issues are appropriate for one or more different approaches to qualitative research and can offer further evidence of rigor in some contexts.

7. Prolonged engagement and / or strategies for 'persistent observation'. The 'cross-sectional' 'one moment in time' approach of research, regardless of whether the research questions are being answered using quantitative or qualitative data, has been subject to increasing critique in many areas of applied social and organizational research (Nimon \& Astakhova, 2015). There are occasions where analysis of a one-moment-in-time phenomenon is justified but, in research that seeks to answer questions about 'why' and 'how' phenomena occur, a research design and research process that enables prolonged engagement with the research context will be more likely to offer a rigorous answer to the questions posed.

8. Paradigmatic/theoretical positioning is another useful indicator of rigor. Following Rocco (2010) my position is that most research paradigms, including those with an inductive or abductive approach to theory (Gold, Walton, Cureton \& Anderson, 2011), require a conceptual framework, grounded in the literature base, if the work is to avoid the charge of being informed only by pragmatic considerations. Such a theoretical or conceptual positioning also enables authors to provide a meaningful discussion of the significance of and implications of their study (BradburyJones, Taylor, \& Herber, 2014).

9. Triangulation is a concept that often appears in qualitative studies and Muir (2014) provided an example of this within the HRD field. We include it here as a possible characteristic of rigor, but argue that it is not always appropriate or helpful as bringing together different data sources to achieve comparison and mutual confirmation may be unsuitable where breadth and depth are prioritized (Fetters \& Molina-Azorin, 2017).

10. Peer debriefing, where researchers discuss their work with disinterested peers who commit to question the research approach in a consistent and systematic fashion are a further means to demonstrate rigor through making aspects of the research explicit as well as a critical evaluation of the patterns that are identified and the analysis process (Cho, Park, Ju, Han, Moon, Park, Ju, \& Park, 2016). For some newer scholars, the dissertation advisor might fulfil this role and the peer review process for good quality journals provides a further opportunity for such procedures and challenge.

\section{Conclusion}


As the field of HRD scholarship continues to mature and develop, we seek to attract submissions from researchers committed to investigating the interaction of HRD practices and processes with wider social and employment experiences. We commit to publishing research that addresses curious questions about learning and development in work-related settings. Following Denzin (2017), I acknowledge that there will be occasions where good quality qualitative work will 'unsettle' traditional concepts of what counts as legitimate research and evidence. We acknowledge the likelihood that worthy and significant findings may require the use of newer research methods although these are frequently met with initial scepticism. I agree with Tracy (2010) that good research should reflect credibility, resonance and 'rich rigor' as a basis for an ethical and meaningful contribution to HRD knowledge, scholarship and practice. In this editorial, I set out six 'big ticket' criteria of rigor in qualitative research and four further indicators that authors and reviewers may consider as they continue to develop and evaluate the quality, trustworthiness and credibility of qualitative inquiry.

\section{References}

Barusch, A., Gringeri, C., \& George, M. (2011). Rigor in Qualitative Social Work Research: A Review of Strategies Used in Published Articles, Social Work Research, 35, 11-20. https://doi.org/10.1093/swr/35.1.11

Bradbury-Jones, C., Taylor, J., \& Herber, O. (2014). How theory is used and articulated in qualitative research: Development of a new typology. Social Science and Medicine, 120, 135-141. http://doi.org/10.1016/j.socscimed.2014.09.014

Braun, V., \& Clarke, V. (2006). Using thematic analysis in psychology. Qualitative Research in Psychology, 3, 77-101. http://doi.org/10.1191/1478088706qp063oa

Burkett, K. W., \& Morris, E. J. (2015). Enabling trust in qualitative research with culturally diverse participants. Journal of Pediatric Health Care, 29, 108-112. http://doi.org/http://dx.doi.org/10.1016/j.pedhc.2014.06.002

Cho, Y., Park, J., Ju, B., Han, S. J., Moon, H., Park, S., Ju, A. \& Park, E. (2016). Women leaders' worklife imbalance in South Korean companies: A collaborative qualitative study. Human Resource Development Quarterly, 27, 461-487. doi: 10.1002/hrdq.21262

Dellinger, A. B., \& Leech, N. L. (2007). Toward a unified validation framework in mixed methods research. Journal of Mixed Methods Research, 1, 309-332.

Denzin, N. K. (2017). Critical qualitative inquiry. Qualitative Inquiry, 23, 8-16. http://doi.org/10.1177/1077800416681864

Denzin, N. K., \& Lincoln, Y. S. (Eds.). (2011). The Sage handbook of qualitative research (4 ${ }^{\text {th }}$ ed.). London: Sage.

Fetters, M. D., \& Molina-Azorin, J. F. (2017). The journal of mixed methods research starts a new decade. Journal of Mixed Methods Research, 11, 3-10. http://doi.org/10.1177/1558689816682092

Gold, J., J. Walton, P. Cureton, and L. Anderson. (2011). Theorising and Practitioners in HRD: The Role of Abductive Reasoning. Journal of European Industrial Training 35, 230-246. doi:10.1108/03090591111120395.

Glaser, B. G., \& Strauss, A. L. (1967). The discovery of grounded theory: Strategies for qualitative research. New York: Aldine de Gruyter.

Hart, P. (2000). Requisite variety: the problem with generic guidelines for diverse genres of inquiry. Environmental Education Research, 6, 37-46. doi.org/10.1080/135046200110476

Henry, P. (2015). Rigor in qualitative research: promoting quality in social science research. Research Journal of Social Sciences, 4, 25-28.

Miller, T., Birch, M., Mauthner, M., \& Jessop, J. (Eds.). (2012). Ethics in qualitative research. Sage. Mueller, M. B., \& Lovell, G. P. (2015). Theoretical constituents of relatedness need satisfaction in 
senior executives. Human Resource Development Quarterly, 26, 209-229.

http://doi.org/10.1002/hrdq.21205

Muir, D. (2014). Mentoring and leader identity development: A case study. Human Resource Development Quarterly, 25, 349-379.

Nelson, J. (2016). Using conceptual depth criteria: addressing the challenge of reaching saturation in qualitative research. Qualitative Research (on line) DOI: 10.1177/1468794116679873

Nimon, K. F., \& Astakhova, M. (2015). Improving the rigor of quantitative HRD research: Four recommendations in support of the general hierarchy of evidence. Human Resource Development Quarterly, 26, 231-247.

Onwuegbuzie, A. J., \& Leech, N. L. (2007). A call for qualitative power analyses. Quality \& Quantity, 41, 105-121.

Saunders, M., Lewis, P., \& Thornhill, A. (2016). Research methods for business students (7th ed.). Harlow: Pearson Education Limited.

Strauss, A., \& Corbin, J. (2015). Basics of qualitative research: Grounded theory procedures and techniques $\left(4^{\text {th }}\right.$ ed.). London: Sage.

Tracy, S. J. (2010). Qualitative inquiry: Eight "big-ten" criteria for excellent qualitative research. Qualitative Inquiry, 16, 837-851

Tosey, P., Lawley, J., \& Meese, R. (2014). Eliciting metaphor through clean language: An innovation in qualitative research. British Journal of Management, 25, 629646.http://doi.org/10.1111/1467-8551.12042

Walby, K., \& Luscombe, A. (2016). Criteria for quality in qualitative research and use of freedom of information requests in the social sciences. Qualitative

Research. https://doi.org/10.1177/1468794116679726

http://doi.org/10.1177/1468794116679726

Wang, J., \& Roulston, K. J. (2007). An alternative approach to conceptualizing interviews in HRD research. Human Resource Development Quarterly, 18(2), 179-210.

http://doi.org/10.1002/hrdq.1199 